\title{
Challenges of Parental Involvement Within a Health Promoting School Framework in New Zealand
}

\author{
Tracy Clelland, ${ }^{1}$ Penni Cushman, ${ }^{1}$ and Jacinta Hawkins ${ }^{2}$ \\ ${ }^{1}$ School of Physical Education and Sport, College of Education, University of Canterbury, Private Bag 4800, \\ Christchurch 8140, New Zealand \\ ${ }^{2}$ School of Business, Faculty of Law, Business and the Creative Arts, James Cook University, Townsville Campus, QLD 4811, Australia
}

Correspondence should be addressed to Tracy Clelland; tracy.clelland@canterbury.ac.nz

Received 26 February 2013; Revised 14 August 2013; Accepted 14 August 2013

Academic Editor: Gwo-Jen Hwang

Copyright (c) 2013 Tracy Clelland et al. This is an open access article distributed under the Creative Commons Attribution License, which permits unrestricted use, distribution, and reproduction in any medium, provided the original work is properly cited.

\begin{abstract}
The study sought to identify key issues regarding parental involvement within a health promoting school (HPS) approach directed at addressing children's nutrition and physical activity. A case study research design was used, involving six primary schools in Auckland, New Zealand. Data were collected via six individual interviews with principals, six group interviews with a total of 26 teachers, 13 focus groups with a total of 92 children, and a survey of 229 parents. The study found that while schools agreed on the importance of schools and parents promoting the same healthy behaviours, there was a lack of agreement on the role of school staff in educating parents. School principals identified issues around managing the food brought from home and the extent to which they should regulate types of food. Parents stressed the importance of modelling healthy food and exercise practices in the home environment but identified factors that often made this difficult, a scenario that did not go unnoticed by their children. It is recommended that parental involvement be encouraged and supported so that schools and families can achieve consistency in health promotion practices across both school and home environments.
\end{abstract}

\section{Introduction}

The health promoting schools (HPS) initiative maintains that in order to successfully promote the long-term health and wellbeing of their students, schools must work closely with parents and the local community [1]. Ultimately, home and school are the two major realms for promoting healthy lifestyles among students. Moreover, if the schools health education classes are to be effective, classroom learning must be reflected and supported in other settings such as the home. Evaluations of health promotion activities and events that have been based solely in the school have, in the past, reported disappointing outcomes. Although student knowledge has increased, long-term behavioural changes have not been evident $[2,3]$.

The health promoting schools (HPS) framework utilises health promotion concepts and incorporates three synergistic elements: curriculum learning and teaching, the ethos and environment of a school, and links with parents and the wider community $[4,5]$. This shift in approach from standalone health education to health promotion across many schools and their wider communities worldwide has placed accountability on schools, teachers, and management to foster environments, relationships, and policies that sustain HPS [6]. Within the sphere of stakeholder participation in effective school-based health promotion, parental involvement is a highly important success factor $[1,5,6]$. In the case of students' nutritional health, for instance, parents play a vital role as caregivers and food providers. Developing effective partnerships with parents, however, has been identified as the most challenging part of bringing the necessary collaborative impetus to school-based health promotion [7].

This concern was the impetus for the study reported in this paper. In an effort to gain a better understanding of the challenges associated with bringing parental involvement into the HPS framework, this study set out to explore the perceptions that school staff, parents, and children held of one another's roles with respect to developing, implementing and 
sustaining health education and promotion that focused on nutrition and physical activity.

\section{Background Literature}

In the New Zealand school curriculum [8], the principles of health promotion clearly underpin teaching and learning in health education. The curriculum document states that because the health and wellbeing of students affect their academic achievement and can, therefore, compromise equality of educational opportunity, schools must address the broad health issues that affect students' learning. Moreover, the document promotes collaboration between schools and parents/school communities in realising this aim. The importance of schools working with parents is also documented in New Zealand's National Educational Guidelines (NEGs) [9]. The guidelines include national education goals and outline two key objectives for schools in relation to health education and promotion. First, schools must ensure that students are healthy in order to optimise their learning, and second schools need to work with parents in educating their children about health.

Schools benefit from taking a proactive approach to engage parents and families in their activities and decision making because parents can contribute skills, expertise, and, most importantly, information about their child and (hopefully) the home environment. Parents are also more likely, through this approach, to develop greater understanding of health issues, and the programmes used within the school to address them, which in turn enables parents to reinforce at home the knowledge and skills learned at school.

Partnerships between schools and parents are likely to be influenced by the way in which schools promote parental involvement. It seems that most schools use the same strategies for all parents, irrespective of parental needs, social class, and individual circumstances $[10,11]$. For example, New Zealand schools typically disseminate newsletters as a mechanism for communicating with parents, yet those who are refugees, new migrants, have literacy problems or speak English as a second language and may not understand the information provided to them. Essentially, schools' strategies to promote parental involvement are usually constructed from their own perspectives and value positions, which do little to encourage parents into a more proactive partnership or to develop a more inclusive participatory role for parents [6]. In order to involve parents, however, schools need to be empathetic to the world view of those parents. Decision making regarding suitable health promotion strategies for the school should account for the cultural and linguistic diversity of the school community, and recognise the socioeconomic and sociocultural circumstances of students and their families [12]. Hart et al. [13] note that the impact of socioeconomic status on nutritional knowledge and access to affordable healthy food is well documented.

Without the necessary knowledge and motivation to undertake an educative role, parents might struggle [13]. In the case of food and nutrition education, parents need to be aware that a range of factors influence the ability of their children to comply with dietary guidelines, and they also need the skills needed to bring about dietary change. In addition, it is unclear if parents are fully cognisant of the relationship between sound nutrition and regular physical activity and students' ability to learn. Research shows that students' acceptance of foods reflects what is being modelled by parents and siblings and that eating nutritious meals as a family can increase children's consumption of vegetables and lower the consumption of high-fat foods $[14,15]$. This research emphasises the importance of parental modelling. The New Zealand Health Sponsorship Council (HSC) reports that parents' eating behaviours are often less healthy than the behaviours they try to encourage in their children [16]. Similarly, physical activity in children appears to be affected by parental attitudes and behaviours. Children tend to be more active when parents model physical activity and support their participation in activities [17, 18].

On the other hand, students have the potential to improve family health behaviours. Hopkins [19] observed that children have the ability to instigate changes in their families' and initiate discussions that lead to new behaviours. Evans et al. [20] found that encouraging students to communicate with parents through homework assignments coupled with written materials for parents was effective in increasing childparent discussions about health and in changing parents' health behaviour for the better.

An example of one approach that has been successfully used to encourage parental involvement through activities involving children and parents is Project Energize (for details, see [21]). Project Energize encourages parental involvement through homework, requiring family participation in physical activity. The approach provides opportunities for children to be agents of change and to be acknowledged for their important contributions to the sharing of health ideas, knowledge, and practices.

One of the key aims of the HPS approach is to align the many different layers or aspects of school practice so that they are all health promoting and reinforcing each other. The HPS framework ensures that change is coordinated through the curriculum, the social and physical environments of the school, the involvement of parents, and health agencies and associated policy development. In their account of school approaches to health education in Pacific Island nations, Tagivakatini and Waqanivalu [22] observe the beneficial outcomes that close integration between school, family, community, and government agencies has resulted in. The authors claim that because schools are a central part of Pacific communities, access to those communities and significant proportions of the Pacific Islanders is made relatively easy. Schools in the Pacific typically bring parents, government agencies, school authorities, and key health and education stakeholders together in the interest of the education of their children.

In New Zealand, however, the level of parental involvement and engagement in education is typically disappointing, and, as such, presents a barrier to fulfilling the benefits of the HPS approach to health education [23]. Drawing on the principles of the HPS framework provides a way of gaining that understanding and then ensuring consistent messages. Rowe et al. [24] stress the importance of formulating school 
systems and practices that value the place of the family environment and wider school community in students' education. Parental involvement that is regular and welcomed by the school can "lead to improvements in (the students') attitudes, behaviours, and attendance at school, as well as in their mental health" ([10], page 28).

Rowling and Samdal [15] emphasise that comprehensive planning from the beginning is fundamental to the success of any HPS approach. According to Rowling and Samdal, the involvement of parents from the onset not only empowers parents, staff, and students to utilise their strengths and existing capacities but also provides parents with a sense of ownership of the process and the decisions and practices arising out of it. Feeling disempowered often leads to disengagement with any health promoting schools initiative.

Walton et al. [25] found that although school policies around healthy nutrition were easier to implement in socioeconomically deprived schools because of a lack of parental involvement, this lack of parental involvement compromised opportunities for longer-term impact. Hornby and Witte [26] found that "the most notable gaps" with respect to schools taking the initiative to involve parents "were the lack of specific ideas (on how) to involve parents from diverse backgrounds, the limited focus on parent education, and the minimal training for teachers on working with parents" (page 504).

Although there is abundant information available to help teachers communicate with the parents of their students around academic matters, the lines are more blurred when it comes to health issues. There appears to be little information for teachers on handling these more sensitive and potentially contentious issues and little support for parents seeking to communicate with teachers. Furthermore, parents' views on how their involvement might be sought or encouraged are rarely sought. Acknowledging this gap in the literature is important because two-way interaction is considered central to effective school-parent partnerships [27]. It is this gap that leads to an investigation into the challenges around parental involvement in school-based health promotion.

\section{Method}

The study reported here is part of a larger case study research project on health promotion [28]. Six diverse primary schools in the Auckland area of New Zealand were recruited for the study. Four of these schools were contributing primary schools, catering for students from year 0 to year 6 (ages 511 ), and two were full primary schools, which also include students in years 7 and 8 (ages 11-13). In order to ensure the representation of different socioeconomic sectors, two of the selected schools were classified as low decile, two as middecile, and two as high decile. Eligible schools were invited by letter to participate and once the researcher had received responses from six schools, the list of participating schools was confirmed.

The study had three phases.

(1) Interviews with Principals and Teachers. Individual interviews were conducted with principals. As heads of their schools, the principals provided a view of health promotion at a macrolevel. Following the interviews of each school principal, principals asked their staff for volunteers to participate in a group interview. Group interviews were utilised because teachers are likely to have similar experiences and be able to offer microlevel insights on students and health promotion. It was anticipated that the group interview approach would generate richer and more complex insights than individual interviews, with comments from one teacher prompting responses from others. Interviews were conducted by the principal researcher of the study.

The interviews with the principals and teachers focused on the promotion of health, nutrition, and physical activity within the school. Essentially, the interviews explored howhealth was being promoted or communicated. Each interview began with the question "Please tell me about how health is promoted in your school?" This question provided a broad starting platform for discussion, allowing principals and teachers to respond in accordance with their own experiences and understandings.

(2) Survey of Parents. A self-completion questionnaire, with a covering letter and an information sheet, was sent home (with the child) with the school newsletter. Reply envelopes were provided. These arrangements were tailored to the needs of each school. The questionnaire was designed to investigate parents' perceptions of nutrition and physical activity issues and the influence of school-based health promotion on their children's diet and exercise behaviours.

(3) Focus Group Interviews with Students. Principals randomly selected several classrooms of students from years 68 to participate in the interviews. Parents/caregivers of the students were sent a consent form, together with a covering letter and an information sheet outlining the details of the study.

Students were grouped by age for the interviews. The aim of these group sessions was to explore students' views on health, specifically nutrition and physical activity, and their perceptions of the health promotion activities currently operating in their school. Students under the age of seven were excluded as it was considered unlikely they would have the cognitive maturity or verbal fluency required for focus group discussion.

Table 1 provides a summary of school and participant characteristics.

The interviews with principals, teachers, and students were audio-taped and transcribed. Transcripts were analysed following the coding procedures and identification of themes detailed by Miles and Huberman [29]. This process was completed using the QSR N6 qualitative data management software package. In the reporting of findings, schools are identified as schools A-E and pseudonyms are used for principals', teachers', and students' names to preserve anonymity. The parents' questionnaires were coded and analysed using the SPSS software package.

\section{Findings and Discussion}

Findings are presented under thematic headings. These sections illustrate the perceptions that the participating groups 
TABLE 1: Summary of research participants and data collection methods.

\begin{tabular}{|c|c|c|c|c|}
\hline Participants & Principals & Teachers & Children & Parents \\
\hline Data collection method & $\begin{array}{c}\text { Individual } \\
\text { interview }\end{array}$ & $\begin{array}{l}\text { Group } \\
\text { interview }\end{array}$ & Focus groups & Self-completion questionnaire \\
\hline $\begin{array}{l}\text { School A } \\
\text { (decile 10) }\end{array}$ & 1 & 4 & $\begin{array}{c}3 \text { groups; } \\
25 \text { children }\end{array}$ & 76 \\
\hline $\begin{array}{l}\text { School B } \\
\text { (decile 9) }\end{array}$ & 1 & 8 & $\begin{array}{l}3 \text { groups; } \\
18 \text { children }\end{array}$ & 53 \\
\hline $\begin{array}{l}\text { School C } \\
\text { (decile 5) }\end{array}$ & 1 & 4 & $\begin{array}{l}2 \text { groups; } \\
13 \text { children }\end{array}$ & 46 \\
\hline $\begin{array}{l}\text { School D } \\
\text { (decile 4) }\end{array}$ & 1 & 5 & $\begin{array}{l}1 \text { group; } \\
8 \text { children }\end{array}$ & 13 \\
\hline $\begin{array}{l}\text { School E } \\
\text { (decile 1) }\end{array}$ & 1 & 3 & $\begin{array}{l}3 \text { groups; } \\
22 \text { children }\end{array}$ & 13 \\
\hline $\begin{array}{l}\text { School F } \\
\text { (decile 1) }\end{array}$ & 1 & 2 & $\begin{array}{l}1 \text { group; } \\
6 \text { children }\end{array}$ & 28 \\
\hline $\begin{array}{l}\text { Total } \\
\text { Six schools, } \\
351 \text { participants }\end{array}$ & $\begin{array}{l}6 \text { interviews; } \\
6 \text { principals }\end{array}$ & $\begin{array}{l}6 \text { interviews; } \\
26 \text { teachers }\end{array}$ & $\begin{array}{l}13 \text { focus groups; } \\
92 \text { children }\end{array}$ & 229 parents \\
\hline
\end{tabular}

Note: decile is a measure of the socioeconomic status (SES) of a school's catchment area. Decile 1 is the highest SES and decile 10 is the lowest.

held of schools' and parents' roles in promoting healthy diets and exercise among students, the ease with which schools were forming health promotion partnerships with parents, and the extent to which schools and homes seemed to have aligned views of healthy nutrition and exercise.

4.1. The Roles of Schools and Parents in Health Promotion. Interviews with principals and teachers showed that they perceived their primary role in school-based health promotion to be that of educating students. According to principals and teachers, a secondary role of schools is to facilitate health communication between students and their parents. They claimed that students play an integral role in communicating information they have learnt at school to their parents, a view that aligns with the findings of Evans et al. [20] that child-initiated communication can be an effective means of teaching parents about health. Teachers viewed parents as being responsible for the care of their children, ensuring that health practices were maintained in the home environment and educating children in relation to healthy behaviours. Students identified their teachers as people from whom they learn about health and school as an environment in which they study and engage in healthy practices.

Parents across all schools expected schools to develop students' understanding of health, through teaching skills needed for health, motivating students to engage in healthy behaviours, and offering opportunities that would encourage these outcomes. Similar to teachers, parents saw themselves as being responsible for the care of their children, including providing nutritious meals and encouraging physical activity, educating them on health topics, and ensuring positive practices are supported in the home environment. Parents, furthermore, considered role modelling healthy behaviours as important; a view which supports the research showing that parental modelling is a powerful mechanism for promoting desired behaviours [16]. Of interest is the finding that while many parents stated they worked to ensure their children ate well and were physically active, they admitted to eating poorly and, more commonly, being physically inactive themselves. These mixed messages that parents were providing to their children did not go unnoticed.

Debbie: It's important (for parents) to be role models for their children.

Melissa: If parents aren't eating healthy and exercising, why would their children, because they are not setting a good example.

(Children, age 11, School F).

Furthermore, some students communicated negativity towards engaging in healthy eating and exercise practices that were not modelled by their parents.

Interviewer: Do you think your parents do enough exercise?

Kyle: My mum and dad do not do any.

Siaki: My dad does not.

Sio: My dad tells us to do it but he does not do it.

Interviewer: How does it make you feel if your parents do not do it but you have to?

Sio: Angry.

Lee: I'd be like embarrassed. ..no frustrated.

Kyle: I'd say, nah. . let us not do exercise.

Interviewer: Why would you be frustrated?

Sio: 'Cause you do not want to do it.

Kyle: And they are forcing you.

Interviewer: How would you feel if they (exercised) with you? 
Sio: I'd feel happier.

(Student, aged 9, School E).

One view expressed by teachers was that the reason why some parents either did not promote healthy behaviours or provided mixed messages was because parents lacked the knowledge, skills, and abilities to communicate messages and engage in practices consistent with those promoted at school. Parents at all schools acknowledged difficulties promoting healthy behaviours to their children, but their reasons included factors not alluded to by school staff. These reasons included lack of time to prepare food, lack of financial ability to purchase healthy food, and mixed messages about healthy food received through the media.

Jonno: Sports sponsorship should set better standards; for example, United Soccer gives every boy "Player of the Day" a free MacDonalds (sic) burger. MacDonalds (sic) is the major sponsor; so what mixed messages are we actually giving kids here? that is, Fast Food chains should not be allowed to sponsor sports.

(NZ European parent, School C).

The different reasons expressed by parents and staff, for healthy behaviours not being promoted at home, illustrate that it is imperative that school staff does not make assumptions about parental factors that hinder health promotion messages and collaboration between parents and the school. Comprehensive planning of health promotion initiatives is crucial, a view supported by Rowling and Samdal [15] who identify "planning from the beginning" as fundamental to the success of any HPS approach.

4.2. Interplay of Home and School Influences. In the case of food and nutrition in particular, there is a strong interplay between home and school. Students eat lunch and snacks at school that are typically brought from home. Teachers reported having little control over students' homemade lunches, regularly observing students eating packaged foods of low nutritional value, such as potato chips and muesli bars. While there are numerous reasons students bring foods to school with little nutritional value, teachers suggested parents' poor nutritional knowledge was a key factor.

There was a range of views on how to address such issues with principals and teachers highlighting the limitations of their authority in dictating what students should eat and noting that policing foods is problematic. In relation to controlling lunches, the schools in the study took a variety of positions. School E, an HPS school, prohibits certain foods, whereas two schools, D and F, do not control foods. Schools $\mathrm{A}, \mathrm{B}$, and $\mathrm{C}$ have no official policies, but do informally monitor what children are eating and may confiscate sweets and junk food items. With policing foods being deemed problematic, so was the role of the school in dealing with parents:

Geoff: You know, that's a can of worms...We'd end up going through their lunch boxes... and that's just getting too intrusive. I do not agree with that.

(Principal, School D).
Nuru: I do not think it's easy to approach any parent with their children about giving them food at school. Sometimes teachers tend to stay away from contacting parents for that reason because it's very hard to tell them; what are you going to tell them?

(Teacher, School D).

Teachers reported that schools often monitored lunches brought from home. For example, School E had achieved positive outcomes by prohibiting certain foods. On the other hand, School C had no official policies, but confiscated certain foods such as carbonated ("fizzy") drinks.

Anita: The school policy now bans fizzy drinks, bans all sorts of things.

(Teacher, School E).

Sophia: There is a rule that you are not allowed, and children have brought huge bottles, like two litre bottles of fizzy and that is taken off them and any big bags of chips. ..we do monitor that sort of thing.

Greer: Lollies and those things that we have found in the playground.

Sophia: They are taken and often kept.

(Teachers, School C).

In some cases, teachers found themselves in a position where they considered it necessary to approach parents about lunches. According to Fatima, a teacher from School E, teachers needed to step in and "educate" parents when they regularly observed students with unhealthy lunches.

We see this poor nutrition... and we need to contact their parents. I strongly believe the first step is educating parents. We talk to them and we explain "No good food, no brain." They can provide. . .cheaper food and healthier food and I explained to them what I mean.

The fact that students were coming to school with foods that teachers considered unhealthy led to staff in all schools recording and discussing discrepancies between what their schools were promoting and practising through their schoolbased health promotion activities, and what parents were promoting/practising in the homes. Staff's assumption of discrepancies in health promotion between school and home was based largely on what was being observed at school.

4.3. Home-School Partnerships. Staff at all six schools said they often found it difficult to establish and maintain schoolhome partnerships for health promotion because parents were either unwilling or unable to engage in such a relationship, were too busy to do so, or were seemingly disengaged from school and schooling. Staff consequently considered that they had to take the major responsibility for promoting nutrition and physical activity to students.

Angela: I feel really helpless. I feel, like, what can we do with parents, if parents aren't going to get on board? I think it's a huge, huge issue. 
(Teacher, School C).

Brian: Teaching and learning happens in a more efficient way if there is a partnership between home and school, but sometimes it is actually a struggle to make that happen.

(Principal, School C).

As the comments from Angela and Brian show, staff at school $\mathrm{C}$ felt that parents had relinquished their responsibilities to promote or reinforce healthy behaviours, a sentiment evident at all six schools. Furthermore, teachers and principals at the schools suggested that some parents, particularly those from lower socioeconomic backgrounds, tended to undervalue education and health promotion or to be disengaged from both, perhaps because of their own adverse experiences of school or general life stressors. Staff observed that such attitudes affected their students accordingly.

Interviewer: Do you think health promotion carries over into the home environment?

Brian: To what extent that occurs is... partly socioeconomic, in that in lower socioeconomic areas there is less of an appreciation of the importance of education...so in those areas there would be less transference of knowledge from the school to the home or less appreciation of the importance of that acquisition of knowledge. .. It's easy to say, to make a statement "home/values/school." Well, that is actually not always the case. When adults have appreciated the need to focus on nutrition and fitness that (is what) will be passed more on to the children. If you teach kids, then they will end up growing up with it, and they'll go into adulthood with it, but in fact it's the adults (at home) who teach them, who give them those perceptions or lack of those perceptions.

(Principal, School C).

4.4. Facilitating Parental Involvement. A key challenge to encouraging parental involvement is the issue of whose role it is to educate parents so they are equipped to support their children in learning about health. For one principal, educating parents was a community problem rather than an educational one. For another, educating parents was beyond the scope of his school's services.

Scott: It's not an educational issue as such...it's a community problem, a society problem. I do not personally see it as being part of the school's role...particularly working with parents.

(Principal, School A).

Geoff: Well, I mean, we have a good, arguably, we have a site where it can be delivered, but whose job is it? I suppose. .. if we're trying to get parents educated, I suppose we're looking at health professionals. If we're looking at the children educating the parents, which I think happens a bit, then. . teachers have a big role in that they deliver health programmes to children. But... as teachers, we do not cater for parents.
(Principal, School D).

Principal Russell similarly maintained that educating parents is not the school's core business and that the underlying issue is parents taking-or not taking-responsibility for themselves and their families.

Russell: When people start taking responsibility for themselves, I think it's like us making stands on certain issues, as a school, this is the parents' job. You're abdicating your responsibility as parents by putting it onto the school, but that is not what our core business is and what we're about. So (on) personal health issues, I think communities and people have to start taking some responsibility for themselves.

(Principal, School F).

In contrast to the other principals, Brian regarded educating parents as an important part of the school's role.

Brian: I think actually it is very important...we are in the business of education. We deal with parents all the time, and we regard part of our job at school is to educate parents, as well as kids.

(Principal, School C).

The principals of Schools B and E suggested other methods of addressing the issue of parental involvement, such as students promoting health to parents and government-led approaches to health education for parents.

\section{Implications and Conclusions}

Health promotion in schools will only be effective if schools ensure that all three components of the HPS approach are working in synergy to effectively enhance the student's wellbeing. The findings of this study lend support to the view that forging strong partnerships between home and school is an important facet of effective health promotion. These partnerships ensure that school staff and parents agree on what constitutes healthy eating and physical activity. Without such partnerships, there is the likelihood of discrepancy between what is communicated to students and practised in the school and what is communicated and practised in the home environments. Moreover, without the school and home promoting the same health messages and behaviours, related school education has little chance of success in terms of longterm lifestyle changes.

Almost all school staff expressed concern and frustration regarding food brought by some children from home. While there was general acknowledgement that many factors contributed to the poor food choices, teachers observed that there was a common view that poor nutritional knowledge of parents was one major factor. There is, of course, more going on at home beyond the provision of school lunches, which suggests that schools and parents would benefit from a greater understanding of each other's health promotion strategies and messages, whether explicit or implicit.

School staff at all 6 schools agreed on a need for parental education but there was a lack of consensus as to who should 
be responsible for its delivery. Some teachers and principals saw the school as having an important role to play while others viewed it as beyond their role and capabilities. This study suggests that there is a need for greater governmental guidance in this area which might also include the involvement of agencies beyond the school in working to educate the community around sound nutritional choices.

The HPS framework views that links with parents and the community is one important facet of school health promotion. This study showed that school staff generally considered students' educational outcomes their primary responsibility and that endeavouring to assist parents with health promotion in the home (or even if they should do so) tends to be a more difficult and somewhat perplexing undertaking that they were not necessarily prepared to engage in. It appears that school staff needs to clarify its understanding around collaborating with parents to promote health.

This understanding, however, is unlikely to be translated into action unless staff has the necessary resources and impetus to exercise this responsibility. Christenson and Sheridan [27] suggest that this impetus is most likely to come from schools providing avenues for parents to instigate interactions with school staff, which they see as essential to developing effective two-way communication between teachers and parents of the kind that limits discrepancies between what is promoted in school and what is practised at home. In order to foster positive and constructive relationships with parents, schools may need to be provided with or to develop strategies that take into consideration the reasons of why parents find it difficult to engage in health promotion in the first instance. There is a need for further research in this field.

Health education for preservice teachers needs to explicitly couch programmes within the health promotion framework [15]. There is also a need for professional development for school personnel that enables them to foster relationships with parents and the wider community.

Particular advantages of the HPS approach are not only its emphasis on creating school-home partnership but also its aim to target children before they are exposed to-and develop-unhealthy practices and to involve parents in that prevention. This study suggests that this is the weakest part of the three-pronged approach and therefore deserving of greater attention.

\section{References}

[1] International Union for Health Promotion and Education (IUHPE), "Achieving health promoting schools: Guidelines for promomting health in schools," Saint-Denis Cedex, 2009, http://www.iuhpe.org/uploaded/Publications/Books_Reports/ HPS_GuidelinesII_2009_English.pdf.

[2] R. L. Atkinson and S. A. Nitzke, "School based programmes on obesity: increase knowledge about nutrition but do not change eating habits by much," British Medical Journal, vol. 323, no. 7320, pp. 1018-1019, 2001.

[3] J. M. Warren, C. J. K. Henry, H. J. Lightowler, S. M. Bradshaw, and S. Perwaiz, "Evaluation of a pilot school programme aimed at the prevention of obesity in children," Health Promotion International, vol. 18, no. 4, pp. 287-296, 2003.
[4] P. Cushman, T. Clelland, and G. Hornby, "Health-promoting schools and mental health issues: a survey of New Zealand schools," Pastoral Care in Education, vol. 29, no. 4, pp. 247-260, 2011.

[5] P. Dickinson, Health Promoting Schools a Review of International Literature and Models of Practice, Ministry of Health, Wellington, New Zealand, 2005.

[6] N. Taylor, F. Quinn, M. Littledyke, and R. Coll, Health Education in Context: An International Perspective on Health Education in Schools and Local Communities, Sense, Rotterdam, the Netherlands, 2012.

[7] J. Inchley, J. Muldoon, and C. Currie, "Becoming a health promoting school: evaluating the process of effective implementation in Scotland," Health Promotion International, vol. 22, no. 1, pp. 65-71, 2007.

[8] Ministry of Education, The New Zealand Curriculum, Learning Media Limited, Wellington, New Zealand, 2007.

[9] Ministry of Education, Ministry of Education.the National Education Guidelines (NEGs), Wellington, New Zealand, 2008, http://www.minedu.govt.nz/educationSectors/Schools/.

[10] G. Hornby and C. Witte, "Parent involvement in inclusive primary schools in New Zealand: implications for improving practice and for teacher education," International Journal of Whole Schooling, vol. 6, no. 1, pp. 27-38, 2010.

[11] G. Crozier, "Is it a case of, "we know when we're not wanted?" The parents' perspective on parent-teacher roles and relationships," Educational Research, vol. 41, no. 3, pp. 315-328, 1999.

[12] Parliament of Victoria Education and Training Committee, Inquiry Into the Potential for Developing Opportunities for Schools to Become a Focus for Promoting Healthy Community Living, Victorian Government Printer, Melbourne, Australia, 2010.

[13] K. H. Hart, A. Herriot, J. A. Bishop, and H. Truby, "Promoting healthy diet and exercise patterns amongst primary school children: a qualitative investigation of parental perspectives," Journal of Human Nutrition and Dietetics, vol. 16, no. 2, pp. 8996, 2003.

[14] S. Dalton, Our Overweight Children What Parents, Schools, and Communities Can Do to Control the Fatness Epidemic, University of California Press, Berkeley, Calif, USA, 2004.

[15] L. Rowling and O. Samdal, "Filling the black box of implementation for health-promoting schools," Health Education, vol. 111, no. 5, pp. 347-362, 2011.

[16] E. Whitfield, F. Samuel, K. Aiolupotea et al., Healthy Eating in New Zealand Families and Whanau, TNS, Auckland, New Zealand, 2007.

[17] C. A. Thompson and E. L. Shanley, Overcoming Childhood Obesity, Bull Publishing Company, Boulder, Colo, USA, 2004.

[18] B. J. Tinsley, How Children Learn to Be Healthy, Cambridge University Press, Cambridge, UK, 2003.

[19] K. Hopkins, "Family communication: a catalyst for socially desired behaviours," PRism, vol. 3, no. 2, pp. 1-15, 2005.

[20] D. Evans, N. M. Clark, M. J. Levison, B. Levin, and R. B. Mellins, "Can children teach their parents about asthma?" Health Education and Behavior, vol. 28, no. 4, pp. 500-511, 2001.

[21] Waikato District Health Board, "Project Energize," 2012, http://www.waikatodhb.govt.nz/events/pageid/2145872029/ Project_Energize.

[22] S. Tagivakatini and T. K. Waqanivalu, "Whole school approaches to health promotion: the Pacific journey," in Health Education in Context: An International Perspective on 
Health Education in Schools and Local Communities, N. Taylor, F. Quinn, M. Littledyke, and R. Coll, Eds., Sense, Rotterdam, the Netherlands, 2012.

[23] N. K. Mohammadi, L. Rowling, and D. Nutbeam, "Acknowledging educational perspectives on health promoting schools," Health Education, vol. 110, no. 4, pp. 240-251, 2010.

[24] F. Rowe, D. Stewart, and S. Somerset, "Nutrition education: towards a whole-school approach," Health Education, vol. 110, no. 3, pp. 197-208, 2010.

[25] M. Walton, J. Waiti, L. Signal, and G. Thomson, "Identifying barriers to promoting healthy nutrition in New Zealand primary schools," Health Education Journal, vol. 69, no. 1, pp. 8494, 2010.

[26] G. Hornby and C. Witte, "Parental involvement in secondary schools in New Zealand: implications for school psychologists," School Psychology International, vol. 31, no. 5, pp. 495-508, 2010.

[27] S. L. Christenson and S. M. Sheridan, School and Families: Creating Essential Connections for Learning, Guilford Press, New York, NY, USA, 2001.

[28] J. Hawkins, Applying marketing theory in educational settings a study of communication processes within school-based health promotions [Ph.D. thesis], Massey University, Auckland, New Zealand, 2009.

[29] M. B. Miles and A. M. Huberman, Qualitative Data Analysis: An Expanded Source Book, Sage, Thousand Oaks, Calif, USA, 1994. 

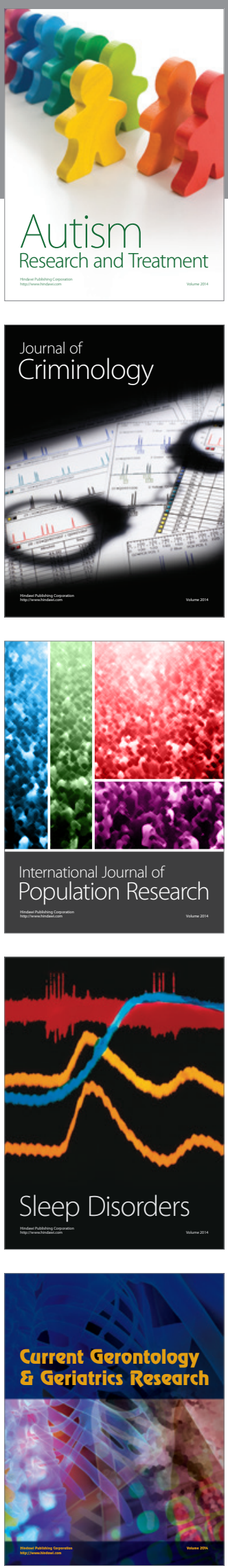
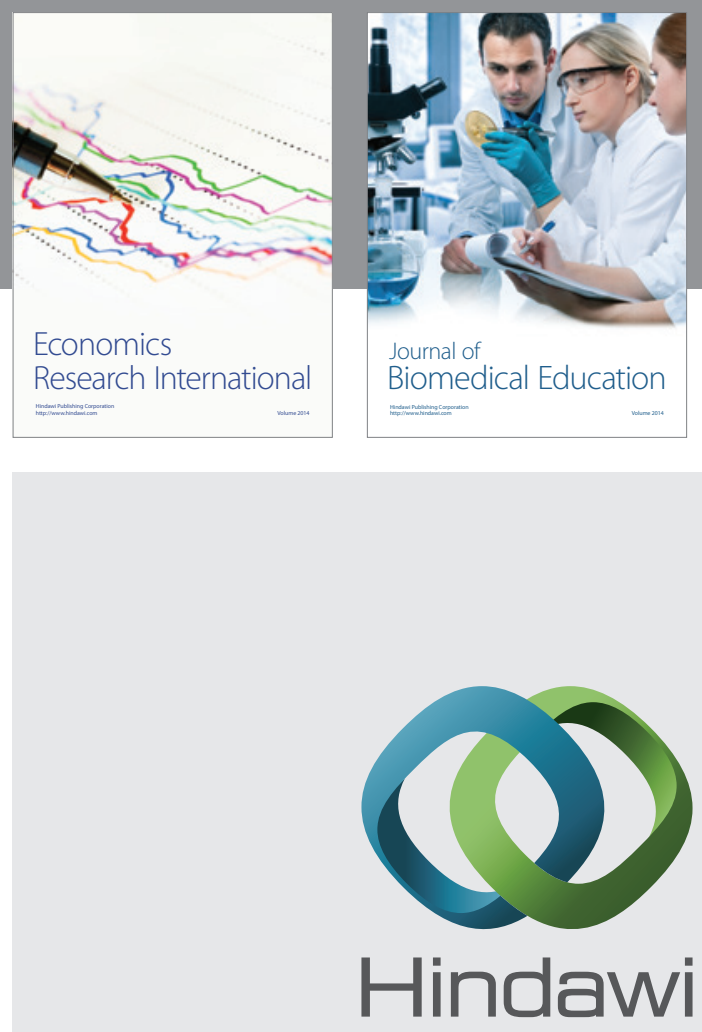

Submit your manuscripts at

http://www.hindawi.com
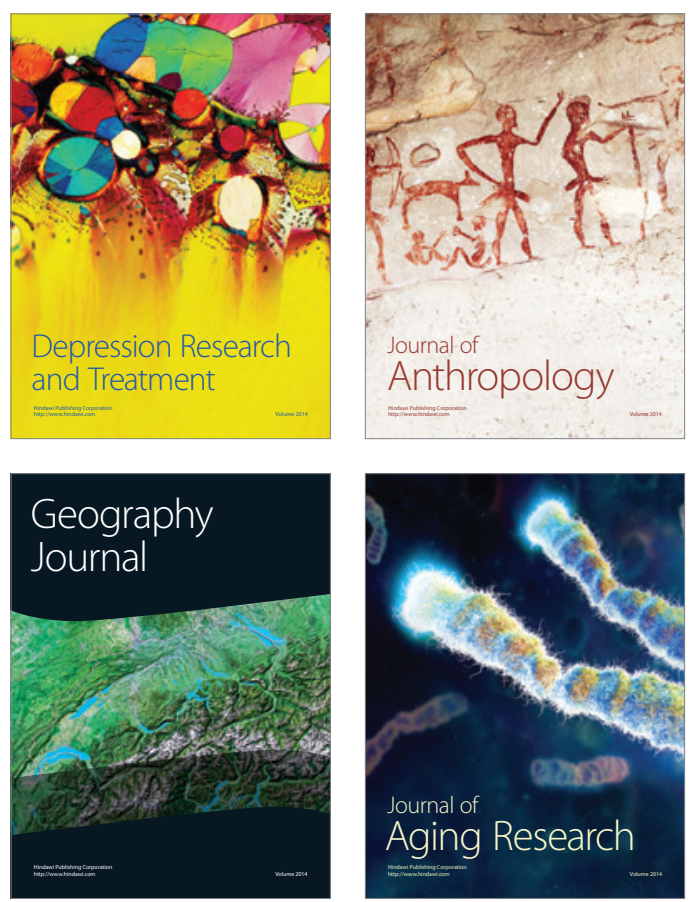
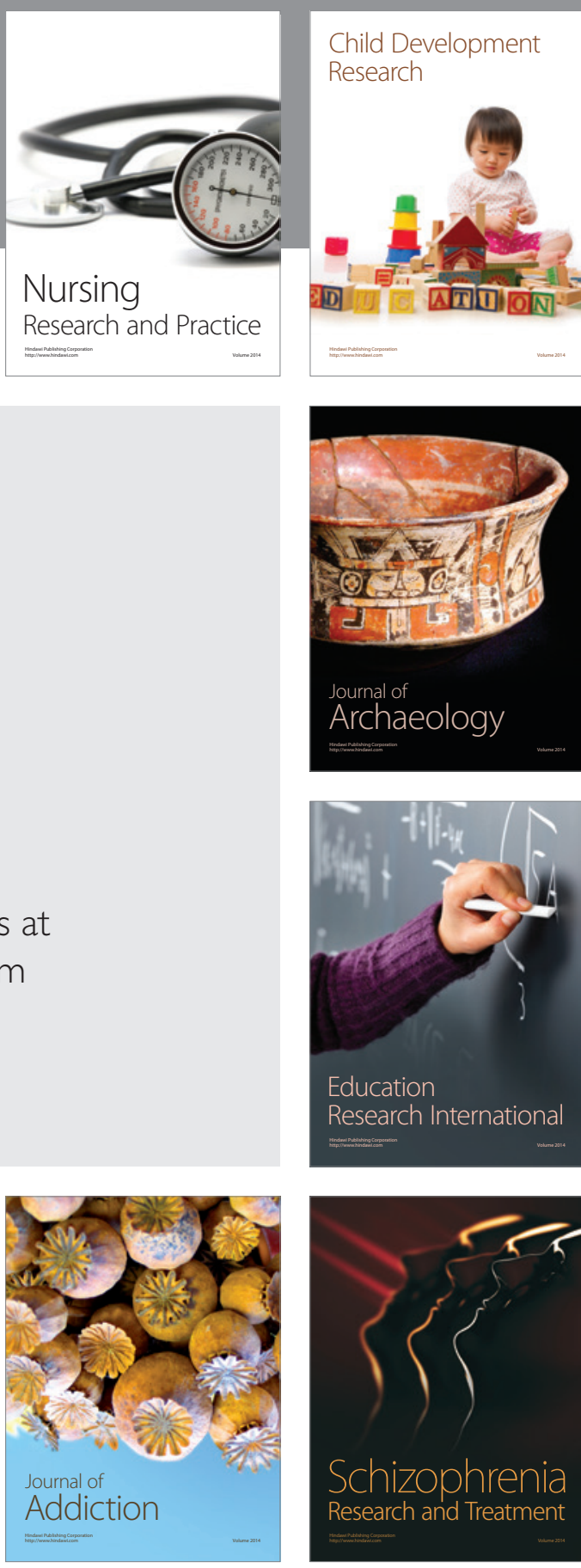

(D)
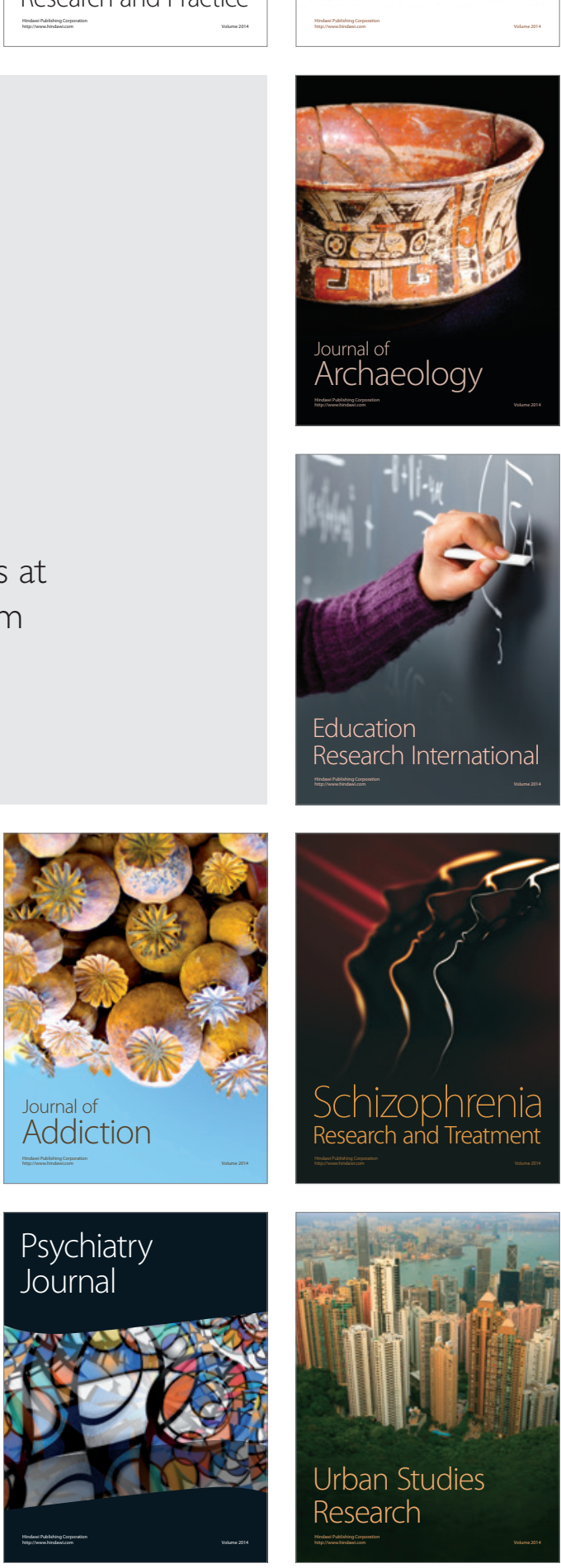